\title{
Optimization Analysis of Multiple Steam Turbines and Condensers in Paper Mill Power Plant
}

\author{
Jinsong Tao ${ }^{1}$, Huanbin Liu ${ }^{1}$, Jigeng $\mathrm{Li}^{1}$, Yongjun $\mathrm{Yin}^{1}$, Yanming Zhou ${ }^{1}$ and Jingiia $\mathrm{Jia}^{2}$ \\ ${ }^{1}$ State Key Laboratory of Pulp and Paper Engineering \\ South China University of Technology \\ Tianhe, Guangzhou, Guangdong, 510640(China) \\ Phone/Fax number: +8620 87111363, e-mail: jstao@scut.edu.cn \\ ${ }^{2}$ Gold East Paper (Jiangsu)Co.,Ltd. \\ No.8, Xing Gang Dong RD., Dagang, ZhenJiang, \\ JiangSu, 212132 (China) \\ Email: j.j.jia@goldeastpaper.com.cn
}

\begin{abstract}
The cooling tower water's influence on turbines and condensers thermal efficiency were researched in this paper and the condenser working condition impact to turbines thermal efficiency was also discussed. Based on the basic model of turbines, condensers and cooling water, the optimization model for the system of turbines, condensers, cooling water and cooling water towers fan was proposed. One paper mill power plant which has multiple turbines, condensers and cooling water towers was taken as a case to verify the optimization model, the result showed that the optimization model was practical and useful for paper mill power plant; it can improve power plant efficiency and bring good economical performance for paper mill.
\end{abstract}

Key words : multiple turbines and condensers; cooling water; load distribution optimization; paper mill

\section{Introduction}

Paper mill, a kind of factory which produce various grade of paper, nowadays are getting more and more heavier energy cost pressure in China because of the rising price of raw energy material as well as the influence of Chinese government energy saving and drainage reduces policies [1]. Power plants, the high level energyconsumption section in paper mill, play an important role on the mill wide energy efficiency. At present, many staffs in paper mill power plant pay more attention on steam turbines, boilers and ignore the condensers influence. Actually, the condensers work conditions have an important impact on steam turbines' efficiency[2].

Condenser, a kind of heat transfer which used to condense vapour into liquid, was widely used in the coalfired power plant in paper mill. Because the main purpose in steam power plant in paper mill is to generate maximum electricity at high efficiency, and the most effective way for reaching this aim is to use condensers. Condensers increase the enthalpy drops and turbine work by lowering the turbine outlet pressure. The lower the pressure, the higher the efficiency and power are. Condensers can be classified in two groups: surface and direct contact. At present, the first type is mostly used in paper mill power plants[3]. And some paper mill power plant staffs like to close the fan of cooling tower to save electrical power; actually, it's not a good way for turbine efficiency.

This paper will analyze the condenser and turbine characteristics and focus on the research of the relation between the steam turbines efficiency with the condensers working conditions as well as the cooling water tower inlet and outlet water temperature and flow rate and get the economical operation set for power plant.

\section{Model Extrapolation}

The principal cycle of the steam engines is Rankine Cycle. A schematic of a simple steam power plant with condenser and its h-s diagram are shown in Fig1.Rankine

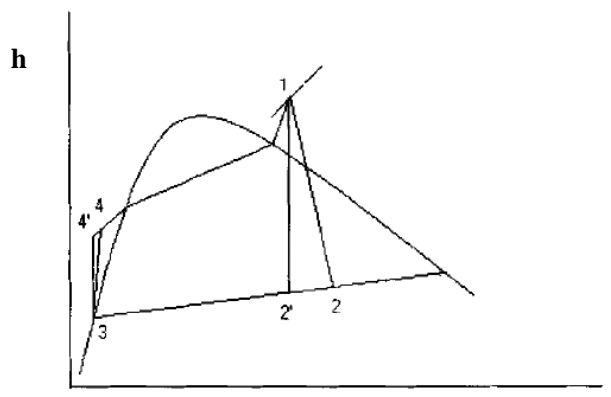

Fig.1 The schematic of a simple steam power plant and it h-s diagram 
Cycle is an ideal cycle where all the process take place as reversible. Actual cycle differs from ideal cycle because of some irreversibilities.

Thermal efficiency of the actual cycle according to Figure 1 is:

$$
\eta_{t h}=\left[\left(h_{1}-h_{2}\right)-\left(h_{4}-h_{3}\right)\right] /\left(h_{1}-h_{4}\right)
$$

And the turbine power is as in (2)

$$
P_{e}=m_{s}\left(h_{1}-h_{2}\right) \eta_{m}
$$

where $\mathrm{h}$ is the enthalpy in $(\mathrm{kJ} / \mathrm{kg}), m_{s}$ the steam mass flow rate in $(\mathrm{kg} / \mathrm{s})$ and $\eta_{m}$ the mechanical efficiency of the turbine.

As seen in (1) and (2), to maximize the thermal efficiency and power, the enthalpy drop in the turbine must be increased. There are mainly two ways to reach this aim. First one is to increase the turbine inlet temperature and pressure, the other one is lowering the turbine exit pressure, in other words to use a condenser as in Figure 2.

From Figure 1 and Figure 2, the heat from the exit steam is as in (3)

$$
Q_{3}=m_{s}\left(h_{2}-h_{3}\right)
$$

And the heat that cooling water gets:

$$
Q_{w}=m_{w} c_{p w}\left(T_{o}-T_{i}\right)
$$

From the equalization of $Q_{3}$ and $Q_{w}$ we get (5)

$$
m_{w}=\left[m_{s}\left(h_{2}-h_{3}\right)\right] /\left[c_{p w}\left(T_{o}-T_{i}\right)\right]
$$

Where $m_{w}$ denotes the cooling water flow rate in $(\mathrm{kg} / \mathrm{s})$,

$c_{p w}$ the specific heat of the water in $(\mathrm{kJ} / \mathrm{kgK})$ and $\left(T_{o}-T_{i}\right)$ the temperature difference of the cooling water.

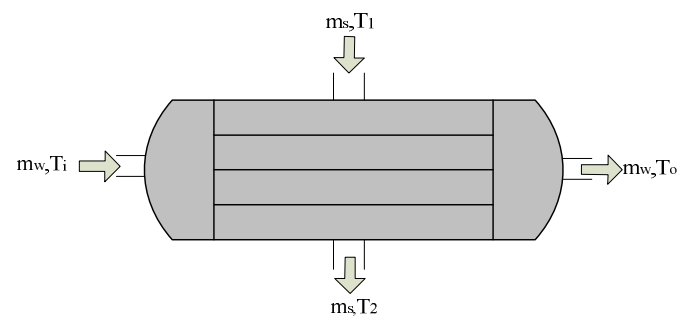

Fig.2 The schematic of a surface type condenser

The heat transferring in condenser is as in (6)

$$
Q=A k \Delta T_{m}
$$

where $\mathrm{k}$ is the heat transfer coefficient in $\left(\mathrm{W} / \mathrm{m}^{2} \mathrm{~K}\right), A_{1}$ the heat transfer area of the condenser in $\left(\mathrm{m}^{2}\right)$ and $\Delta T_{m}$ the log mean temperature difference, as in (7)

$\Delta T_{m}=\left[\left(\Delta T_{i}-\Delta T_{e}\right)\right] /\left[\ln \left(\Delta T_{i} / \Delta T_{e}\right)\right]$

$\Delta T_{i}$ is difference between saturation steam temperature and cooling water inlet temperature $\left(\Delta T_{i}=T_{2}-T_{i}\right), \Delta T_{e}$ is difference between saturation steam temperature and cooling water exit temperature $\Delta T_{e}=\left(T_{2}-T_{o}\right)$.

If we take the length of the cooling water tubes as L, inner diameter of the tube as $\mathrm{d}_{\mathrm{i}}$, outer diameter as $\mathrm{d}_{\mathrm{a}}$ and tube number as n, $A$ can be written as in (8)

$$
A=\pi d_{a} L n
$$

Cooling water velocity in the tubes:

$$
v=m_{w} /\left[\left(\rho \square d_{1}^{2} \square n\right)(\pi / 4)\right]
$$

where $\rho$ is the density of water.

Cooling water heat transfer coefficient is as in (10)

$$
\alpha_{w}=\left(a \sqcup v_{v}^{n} / d_{1}^{m}\right)\left(1+b \square T_{m}\right)
$$

where $T_{m}$ is the mean temperature of the cooling water and $\mathrm{a}, \mathrm{b}, \mathrm{m}, \mathrm{n}$ are the constant factor. If we denote the dirtiness factor as $\varphi$ then

$$
\alpha_{w}^{\prime}=\varphi \triangleright \alpha_{w}
$$

$\varphi$ value can be taken between 0.65 and $0.75[4]$.

The overall heat transfer coefficient $\mathrm{k}$ can be drawn from (12)

$$
1 / k=\left(1 / \alpha_{w}^{\prime}\right)+(\delta / \lambda)+\left(1 / \beta_{s}\right)
$$

where $\delta$ is the tube thickness, $\lambda$ the thermal conductivity of the tube material and $\beta_{s}$ the heat transfer coefficient of the steam $\beta_{s}$ value is taken between 11000 16000 $\left(\mathrm{W} / \mathrm{m}^{2} \mathrm{~K}\right)$.

The power of the cooling tower fan is

$$
P_{f}=P_{r}^{\square} \eta_{f}
$$


where $P_{r}$ the rated power of the fan, $\eta_{f}$ is the fan efficiency.

When we decrease $T_{i}$ through opening the cooling fan, the cooling water will decrease $T_{2}$ which will influence $h_{2}$ and $T_{2}$ can be calculated with the thermal balance with the help of (6), (8) and (12). And the final electrical energy generation optimization model is as in (14)

$$
E=\sum_{i}^{n}\left[m_{s}{ }^{\prime}\left(h_{1}-h_{2}\right) \eta_{m}-m_{s}\left(h_{1}-h_{2}{ }^{\prime}\right) \eta_{m}\right]-\sum_{i}^{n}\left(P_{r} \sqsubset \eta_{f}\right)
$$

\section{Results and Discussion}

There are four boilers and four turbines. Turbine \#1,2,3 and boiler \#1, 2, 3 were built firstly and share a main steam pipe. Turbine \#4 and boiler \#4 were built after several years. Turbines main parameters are as in Table I.

Table I.-Main capacity paramters of tubines

\begin{tabular}{|c|c|c|c|}
\hline & \multirow{2}{*}{ Items } & Unit & \multicolumn{2}{|c|}{$\begin{array}{c}\text { Design capacity } \\
\text { parameter }\end{array}$} \\
\cline { 3 - 4 } & & $\# 1$ & $\# 2,3,4$ \\
\hline Rate power & $\mathrm{kw}$ & 50000 & 80000 \\
\hline Steam pressure & $\mathrm{Mpa}$ & 12.3 & 12.3 \\
\hline $\begin{array}{c}\text { Medium pressure } \\
\text { extracting steam pressure }\end{array}$ & $\mathrm{Mpa}$ & 1.6 & 1.6 \\
\hline $\begin{array}{c}\text { Medium extracting steam } \\
\text { amount }\end{array}$ & $\mathrm{t} / \mathrm{h}$ & 30 & $50 / 50 / 90$ \\
\hline $\begin{array}{c}\text { low pressure extracting } \\
\text { steam pressure }\end{array}$ & $\mathrm{Mpa}$ & 0.6 & 0.6 \\
\hline $\begin{array}{c}\text { low pressure extracting } \\
\text { steam amount }\end{array}$ & $\mathrm{t} / \mathrm{h}$ & 145 & $195 / 195$ \\
\hline Exhaust pressure & $\mathrm{Mpa}$ & 0.007 & 0.007 \\
\hline
\end{tabular}

\section{A. Turbine Efficiency}

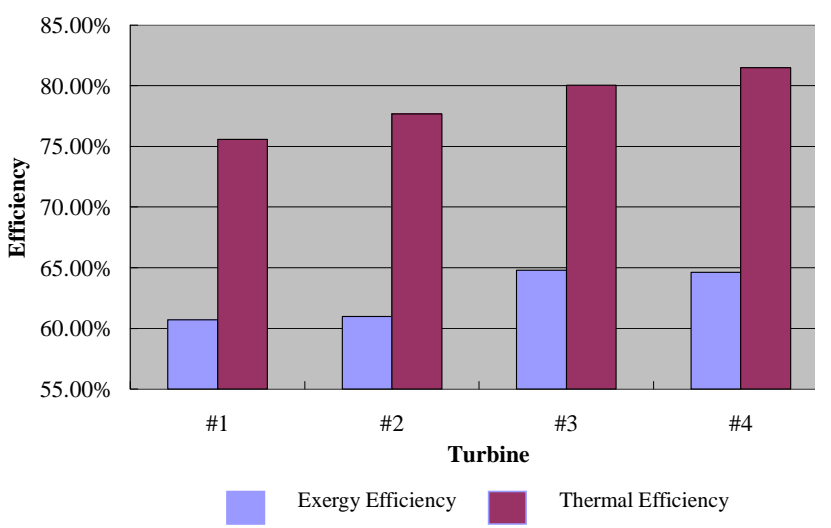

Fig.3 Exergy and Thermal efficiency of the turbines
The turbines exergy and thermal efficiency can be got as Figure 3. Form Table I, we can find turbine \#2, 3, and 4 are the same rated power turbine, but from Figure 3, their themal efficiency are diffirent and turbine \#4 has the highest efficiency and turbine \#1, 2 ,3 theraml efficiency are low.

\section{B. Condenser Operation Parameters}

The condenser operation parameters are as Table II.

Table II.-Condenser operation parameters

\begin{tabular}{|c|c|c|c|c|}
\hline \multirow{2}{*}{ Items } & \multicolumn{4}{|c|}{ Turbine condensers } \\
\cline { 2 - 5 } & 1 & 2 & 3 & 4 \\
\hline $\begin{array}{c}\text { Condenser } \\
\text { Temperature, }{ }^{\circ} \mathrm{C}\end{array}$ & 46.9 & 52.2 & 50.1 & 39.8 \\
\hline $\begin{array}{c}\text { Temperature outlet } \\
\text { cooling water, To, }{ }^{\circ} \mathrm{C}\end{array}$ & 40 & 42.2 & 42.2 & 39.6 \\
\hline $\begin{array}{c}\text { Temperature inlet } \\
\text { cooling water, } \mathrm{T}_{\mathrm{i}},{ }^{\circ} \mathrm{C}\end{array}$ & 29.5 & 30 & 30 & 32.2 \\
\hline $\mathrm{T}_{\mathrm{o}}-\mathrm{T}_{\mathrm{i}},{ }^{\circ} \mathrm{C}$ & 10.5 & 12.2 & 12.2 & 7.4 \\
\hline
\end{tabular}

From Table II, we can find the temperature difference of \#1, 2, 3 between outlet cooling water and inlet cooling water are too big which exceed the normal rang, this is an important cause lead to a low turbine efficiency for trubine \#1, 2, 3.

\section{Cooling Water Tower}

Boiler \#1, 2, 3 and turbine \#1, 2, 3 share one group cooling tower which we named cooling tower group \#1, after extension projects of the paper mill, boiler \#4, and turbine \#4 use one new group cooling tower which we name group \#2. From the data provided by the paper mill power plant staff, the cooling capacity of group \#1 is lack of the demand of turbine \#1,2, 3 condensers; this is another cause to lead to turbine \#1,2,3 low thermal efficiency. But cooling tower group \#2 cooling capacity if excess for turbine \#4, and the staff close group \#2 some fan to save energy.

\section{Optimization Strategy}

From Equation (14), we can adjust the condensers inlet steam and cooling water temperature to optimize the total system thermal efficiency.

For turbine \#4 and cooling water tower group \#2, we find turbine \#4 has high thermal efficiency, and the matched cooling water tower's capacity is excess, so we can run more cooling fan to decease the cooling water's temperature to improve the steam amounts cooled by cooling water, and reduce turbine \#4 extracting steam amounts to let it produce more electricity and produce less extracting steam.

For turbine \#1, 2 and 3, we can decease the amounts which flow into the condensers and improve extracting 
steam amount, decease the condenser temperature, to let turbine \#1, 2 and 3 produce more extracting steam and less electricity.

\section{E. Optimization Results}

To get the good economical performance, the optimization steps were carried out as the following:

First, the else three cooling tower fans in group \#2 cooling tower were opened to cool the water from $32{ }^{\circ} \mathrm{C}$ to $24.5^{\circ} \mathrm{C}$ for turbine \#4, and keep the water flow rate as a constant.

Second, increase steam inlet amounts for turbine \#4 and decease its extracting steam amounts; meanwhile, decrease steam inlet amounts for turbine \#1, 2, and 3 and increase their extracting steam amounts, through turbines
\#4 and turbine \#1, 2, 3 adjustments to keep the total extracting steam amounts as a constant value to meet the production requirements.

Finally, the steam inlet flow rate for turbine \#4 will increase which will result in generating more electricity, but the heat will be carried away by the cooler water through opening three else cooling water fans and the condenser temperature will keep a constant value. Turbine \#1, 2 and 3 condenser temperature will decease with the decease of steam inlet which will lead to generating less electricity.

The condensers operation parameters optimization results were as in Table III.

Table III.- Condensers operation parameter before and after optimization

\begin{tabular}{|c|c|c|c|c|c|c|c|c|}
\hline \multirow{2}{*}{ Items } & \multicolumn{2}{|c|}{ \# 1} & \multicolumn{2}{|c|}{ \# 2} & \multicolumn{2}{|c|}{ \# 3} & \multicolumn{2}{|c|}{ \# 4} \\
\hline & Before & After & Before & After & Before & After & Before & After \\
\hline $\begin{array}{l}\text { Heat transfer } \\
\text { area, } \mathrm{m}^{2}\end{array}$ & 1120 & 1120 & 1380 & 1380 & 1380 & 1380 & 4358 & 4358 \\
\hline $\begin{array}{l}\text { Cooling water } \\
\text { inlet } \\
\text { temperature, }{ }^{\circ} \mathrm{C}\end{array}$ & 29.5 & 29.5 & 30 & 30 & 29.7 & 29.7 & 32 & 24.5 \\
\hline $\begin{array}{l}\text { Cooling water } \\
\text { outlet } \\
\text { temperature, }{ }^{\circ} \mathrm{C}\end{array}$ & 40.5 & 38 & 42.3 & 40.3 & 42.3 & 39.9 & 39.5 & 39.2 \\
\hline $\begin{array}{c}\text { Steam } \\
\text { condensing } \\
\text { temperature, }{ }^{\circ} \mathrm{C}\end{array}$ & 47 & 43 & 52 & 48.4 & 50.1 & 46.2 & 39.8 & 39.8 \\
\hline $\begin{array}{c}\text { Cooling water } \\
\text { temperature } \\
\text { difference, }{ }^{\circ} \mathrm{C} \\
\end{array}$ & 11 & 8.5 & 12.3 & 10.3 & 12.6 & 10.2 & 7.5 & 14.7 \\
\hline $\begin{array}{c}\text { Heat transfer } \\
\text { temperature } \\
\text { difference, }{ }^{\circ} \mathrm{C} \\
\end{array}$ & 6.5 & 5 & 9.7 & 8.1 & 7.8 & 6.3 & 0.3 & 0.6 \\
\hline $\begin{array}{c}\text { Log mean } \\
\text { temperature } \\
\text { difference, }{ }^{\circ} \mathrm{C} \\
\Delta t_{m}\end{array}$ & 11.1 & 8.58 & 15 & 12.6 & 13.1 & 10.6 & 2.3 & 4.5 \\
\hline $\begin{array}{c}\mathrm{K} \\
\text { value }\end{array}$ & 12953.1 & 12953.1 & 12955.6 & 12955.6 & 12957.08 & 12957.1 & 13003 & 13003 \\
\hline $\begin{array}{c}\text { Steam inlet } \\
\text { flow rate, } \mathrm{t} / \mathrm{h}\end{array}$ & 73.9 & 57.1 & 123.26 & 103.1 & 107.5 & 86.9 & 59.8 & 117.2 \\
\hline $\begin{array}{c}\text { Steam flow rate } \\
\text { difference, } \mathrm{t} / \mathrm{h}\end{array}$ & & 16.8 & & 20.1 & & 20.6 & & 57.4 \\
\hline
\end{tabular}

From Table III, the economical performance was list in Table IV, and it can be found there is $660 \mathrm{Kwh} / \mathrm{h}$ electricity will be produced after optimization.

Table IV.- the optimization results for generating more electricity

\begin{tabular}{|c|c|c|c|c|c|c|}
\hline Item & Turbine \#1 & Turbine \#2 & Turbine \#3 & Turbine \#4 & Cooling tower & Total \\
\hline
\end{tabular}




\begin{tabular}{|c|c|c|c|c|c|c|c|c|c|c|c|}
\hline & & & & & & & & & fo & & \\
\hline & Before & After & Before & After & Before & After & Before & After & Before & After & \\
\hline Steam inlet flow rate, $\mathrm{t} / \mathrm{h}$ & 73.9 & 57.1 & 123.26 & 103.1 & 107.5 & 86.9 & 59.8 & 117.2 & & & \\
\hline $\begin{array}{c}\text { Generated electricity, } \\
\text { Kwh/h }\end{array}$ & 11007 & 8643 & 17076 & 14536 & 14806 & 12324 & 8888 & 17390 & 0 & -456 & \\
\hline $\begin{array}{c}\text { Electricity difference, } \\
\mathrm{Kwh} / \mathrm{h}\end{array}$ & & -2364 & & -2540 & & -2482 & & 8502 & & -456 & 660 \\
\hline
\end{tabular}

\section{Conclusion}

The optimization for turbines, condensers and cooling water tower can increase the paper mill power plant electricity generation, and obtain good economical result through adjusting some operation parameters without capital investments. This kind of optimization strategy can be applied to the multiple cooling towers, condensers and turbine paper mill power plants.

\section{Acknowledgement}

The authors would like to acknowledge the financial support of Guangdong-KongHong Key Field Researching Foundation ( Grant No.20070109-2 ) , Guangdong Province Science and Technology Project Foundation (Grant No. 2007B050200010) , Natural Science Foundation of China (Grant No. 20906030) and State Key Laboratory of Pulp and Paper Engineering Youth Innovation Program Foundation, South China University of Technology.

\section{References}

[1] B.Angeles, C. Negro, C. Monte. and E. Fuente. The Challenges of sustainable papermaking, Environmental Science \&Technology, (2004), pp. 414-420.

[2] Y.J.Yin, J.S. Tao, J.G. Li and H.B.Liu. Exergy analysis of Co-supply of Heat and Power system in the pulp and paper mills. in Proceeding of International Conference on Pulping and Papermaking and Biotechnology. 2008. Nanjing, pp.104-109

[3] H. Taniguchi, T. Nakahara and N. Arai, Exergy analysis on combustion and energy conversion processes. Energy, (2005). 30: pp. 111-117.

[4] G. YAN and J. ZHOU, The design and application of evaporation condenser. Refrigeration and Air Conditioning (2003). 3( (3) ): Pp. 43 - 45. 